\title{
Non-traumatic Ischaemic Myelopathy: A Review of 25 Cases
}

\author{
S. W. Kim, MD, ${ }^{1}$ R. C. Kim, MD, ${ }^{2,3}$ B. H. Choi, MD, ${ }^{3}$ S. K. Gordon, MD ${ }^{1}$ \\ ${ }^{1}$ Spinal Cord Injury and ${ }^{2}$ Laboratory Services, Veterans Administration Medical \\ Center, Long Beach, California, ${ }^{3}$ Department of Pathology, University of \\ California Irvine, Irvine, California, USA.
}

\begin{abstract}
Summary
The causes of ischaemic myelopathy are described in 25 patients. Nine developed following surgical manipulation or traumatic laceration of the aorta, 1 following intercostal artery ligation, 3 following aortic aneurysm dissection, 2 following myocardial infarction and/or cardiac arrest, 7 in the absence of any specifically identifiable predisposing factors, and 3 in association with decompression sickness. The degree of clinical recovery was greater among those with incomplete spastic (as opposed to complete flaccid) paralysis and among those in whom sensory loss below the level of injury was incomplete. Despite the diversity of mechanisms that may lead to the development of spinal cord ischaemia, structural damage seems in most instances to affect either grey matter or white matter predominantly. Some of the possible reasons for these preferential sites of damage are discussed.
\end{abstract}

Key words: Ischaemic myelopathy; Paraplegia; Aortic diseases; Spinal vascular disease.

There are only a few analytical studies in the English language literature of large series of patients with ischaemic myelopathy, although a number of isolated examples of spinal cord vascular lesions have been published. The most recent reviews of this type include those of Garland, et al. (1966), Mannen (1966), Henson and Parsons (1967), and Silver and Buxton (1974). The subject has not been treated in any great detail in standard textbooks of neurology (Adams and Victor, 1985) or neuropathology (Adams, et al., 1984; Davis and Robertson, 1985), probably because of the relatively low frequency with which the condition is encountered. Blackwood (1958), for example, was unable to find a single example of arterial softening of the spinal cord among 3737 postmortem examinations conducted over a 50 year period at the National Hospital, Queen Square.

On the arterial side, the better recognised causes of ischaemic myelopathy include recent aortic surgery or traumatic injury, aortic aneurysm dissection, 
Table Clinical data on patients with ischaemic myelopathy

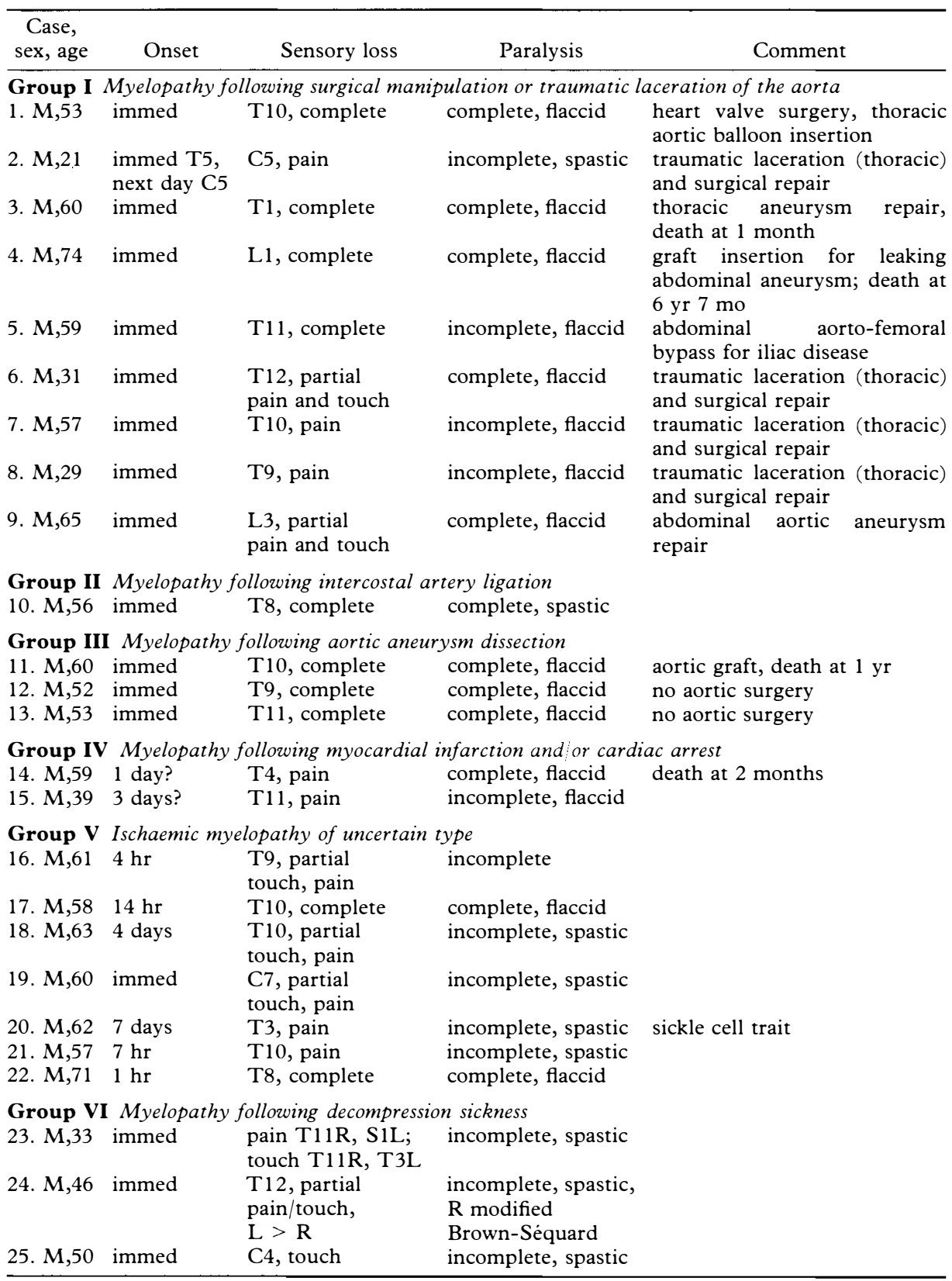

severe hypotension such as that occurring after myocardial infarction or cardiac arrest, atherosclerosis, and, possibly, decompression sickness. Nonetheless, the mechanisms by which these conditions lead to infarction and the nature and distribution of the lesions produced are poorly understood. Thus, for example, although the concept of an anterior spinal artery syndrome is widely discussed, pathologically documented examples of anterior spinal artery occlusion are 
extremely rare (Hughes and Brownell, 1965; Garland et al., 1966; Lazorthes, 1972).

In an effort to shed some light on the mechanisms by which circulatory dysfunction results in the development of damage to the spinal cord and on the nature of the lesions produced, we have reviewed our experience with patients suffering from this form of myelopathy.

\section{Clinical material}

From October of 1971 through to February 1986, 1535 new patients were admitted to the Spinal Cord Injury Service of the Long Beach Veterans Administration Medical Center. Twenty five of these patients, all male, were felt on clinical grounds to be suffering from myelopathy of ischaemic origin. The demographic features of these patients, grouped according to etiology, are indicated in the Table. Nine patients developed myelopathy after surgical crossclamping and/or traumatic laceration of the aorta, 1 after intercostal artery ligation, 3 after aortic aneurysm dissection, 2 after myocardial infarction and/or cardiac arrest, 7 on the basis of spinal vascular disease of uncertain type, and 3 after decompression sickness.

\section{Results}

\section{Group I}

Myelopathy following surgical manipulation and/or traumatic laceration of the aorta (cases 1-9).

Three patients underwent surgical manipulation of the aorta for aneurysm repair, 4 for traumatic aortic lacerations, 1 for thrombo-occlusive aortic disease, and 1 for mitral valve replacement and a coronary by-pass procedure. The thoracic aorta was clamped in 6 and the abdominal aorta in 3. In all patients spinal cord dysfunction was noted immediately postoperatively. Sensory loss was complete in 4 and dissociated (with loss of pain and temperature perception and preservation of tactile sensation) in 3. In 2 (cases 6 and 9) there was partial loss of both tactile and pain perception. Paralysis was judged to be complete in 5 and partial in 4; it was flaccid in 8 and spastic in 1. Although some degree of recovery of function was observed in 4 , in only 1 (case 2 ) was improvement judged to be significant.

Postmortem examination of the spinal cord in case 3 revealed the presence, from $\mathrm{T} 1$ downward, of a centrally placed, sharply circumscribed focus of haemorrhagic necrosis affecting predominantly grey matter (Fig. 1) and containing an abundance of newly formed vascular channels and lipid-laden macrophages and, at the margins, scattered hypertrophied astrocytes. The near-total involvement of the spinal grey and the relative sparing of the white matter were noteworthy.

\section{Group II}

Myelopathy following intercostal artery ligation (case 10).

Immediately postoperatively, following surgical resection of the right eighth 


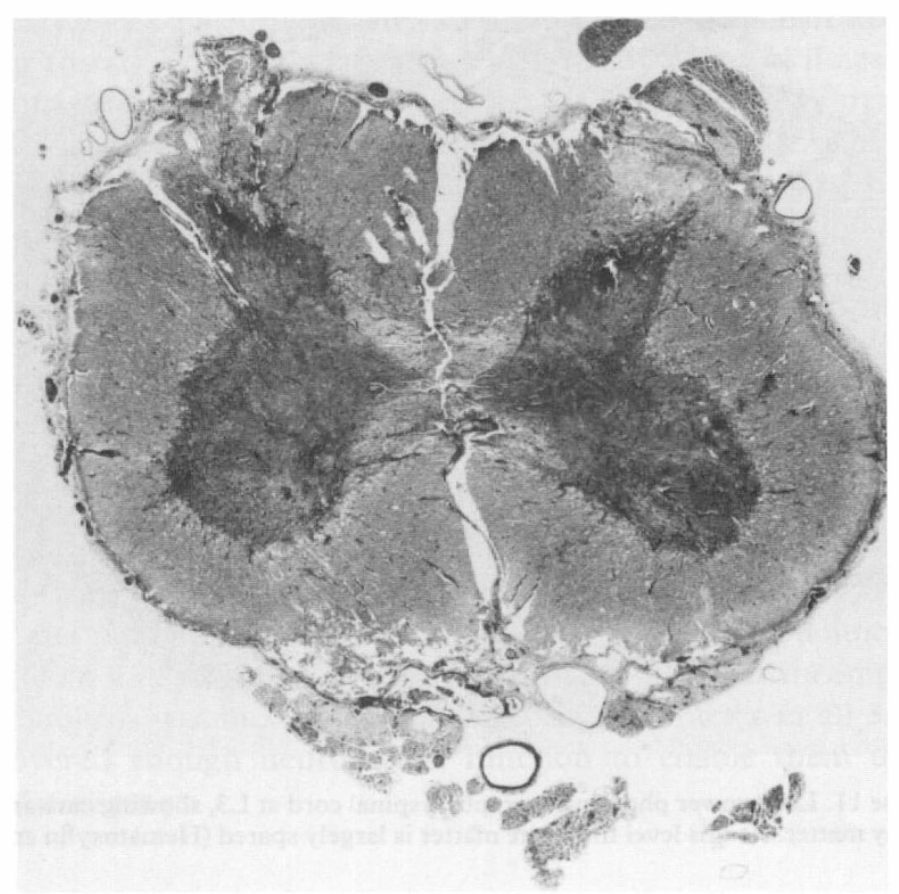

Figure 1 Case 3. Low-power photomicrograph of spinal cord at L5, showing sharply circumscribed areas of haemorrhagic necrosis that are almost exclusively confined to the grey matter (Masson trichrome stain $\times 14)$.

rib that required ligation of the adjoining intercostal artery, the patient was observed to have developed complete sensory loss to T8 and complete spastic paraplegia. Over the ensuing years there was no significant recovery of neurological function.

\section{Group III}

Myelopathy following aortic aneurysm dissection (cases 11-13).

One of the patients in this group suffered a Type I dissection, and 2 of them a Type III dissection, according to the classification of DeBakey et al. (1982). All developed complete sensory loss at lower thoracic levels (T9, T10, and T11), as well as complete flaccid paraplegia. None showed evidence of recovery of neurological function with the passage of time.

Postmortem examination in case 11 revealed the presence of sharply circumscribed cavitary necrosis within most of the spinal grey matter from T10 downward (Fig. 2). Lipid-laden macrophages, reactive thin-walled vascular channels, and occasional hypertrophied astrocytes were identified within or around the cavity. At the upper border of the lesion (T9) there was relative sparing of the white matter and of the ventromedial spinal grey but, from S1 downward, extensive damage was seen within both white and grey matter. 


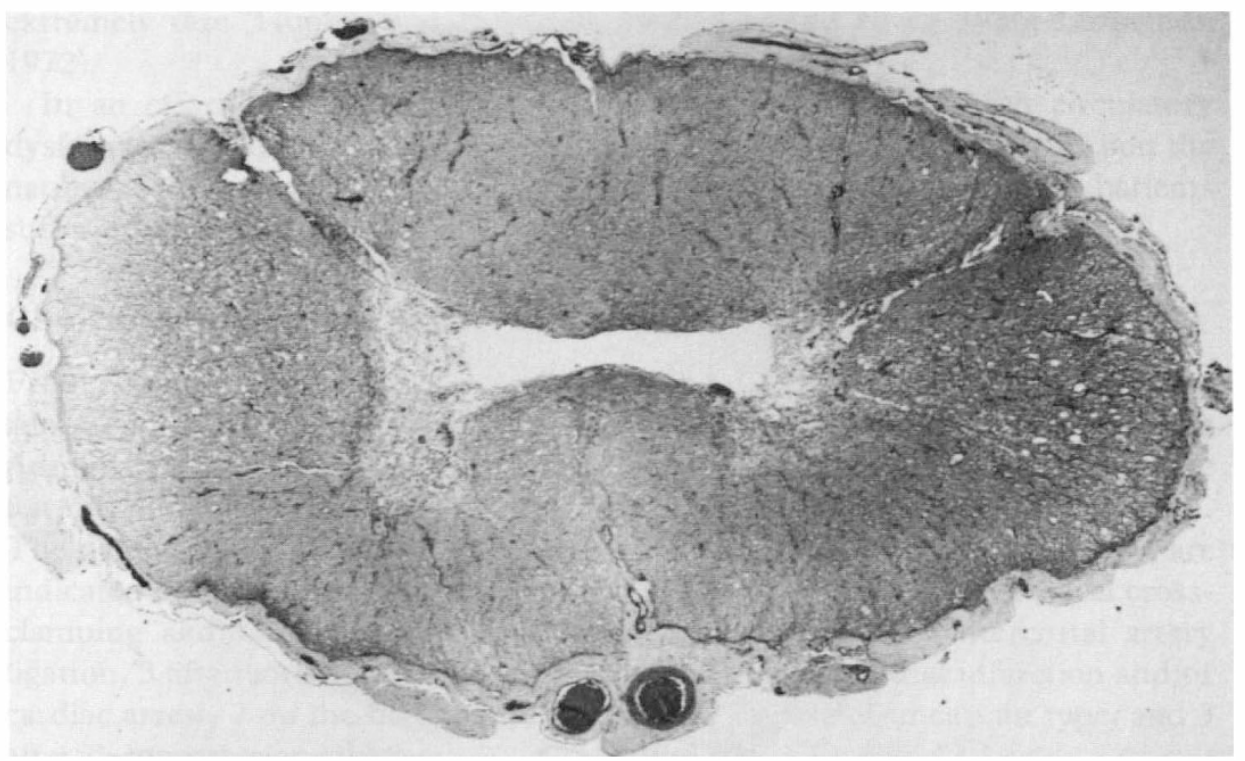

Figure 2 Case 11. Low-power photomicrograph of spinal cord at L3, showing cavitary necrosis within the grey matter. At this level the white matter is largely spared (Hematoxylin and eosin stain $\times 16)$.

\section{Group IV}

Myelopathy following myocardial infarction and/or cardiac arrest (cases 14 and 15).

Both of these patients suffered, soon after the insult, dissociated sensory loss and incomplete, flaccid paraplegia. In each instance an altered level of consciousness in the initial stages of illness precluded accurate observations regarding the rapidity of onset of neurologic dysfunction. Neither showed any evidence of subsequent recovery of neurological function.

Postmortem examination of the spinal cord in case 14 disclosed the presence of extensive tissue breakdown within the spinal grey from T4 downward. Rostrally the lesion extended from the base of the posterior horns into the dorsolateral portions of the anterior horns, with relative sparing of the ventromedial anterior horns and commissural grey. At lower levels there was proportionately greater involvement of the spinal grey (Fig. 3). At the most caudal levels (S4 and below) all of the grey matter, including the commissural grey, was affected.

\section{Group V}

Ischaemic myelopathy of uncertain type (cases 16-22).

Seven patients were assigned to this group on the basis of ischaemic electrocardiographic changes, a history of hypertension, and (in two) a history of diabetes mellitus, and because of the absence of any additional predisposing factors (e.g. aortic surgery, severe hypotension, decompression sickness, 
syphilitic cardiovascular disease, etc.). Thrombus was demonstrated within the aorta in one instance (case 22) by aortography. The course of illness in a few of these patients was similar to that described for atherosclerotic myelopathy by Skinhøj (1954) and by Henson and Parsons (1967). In the absence of pathological data, however, we can only speculate as to the mechanisms by which myelopathy developed in the majority of patients in this group.

The onset of neurological dysfunction was sudden in 2 and protracted (4 hours to 7 days) in 5. Dissociated sensory loss was noted in two. Paralysis was complete and flaccid in 2 and incomplete and spastic in the remaining 5. Two patients within this group showed significant subsequent neurological improvement; both are walking at the present time.

\section{Group VI}

Myelopathy following decompression sickness (cases 23-25).

All 3 of the patients within this group developed paralysis immediately on ascending from a depth of over 100 feet. Sensory loss was incomplete in each instance. Paralysis was incomplete and of spastic character in all 3. Two eventually recovered enough neurological function to enable them to walk with mechanical assistance.

\section{Discussion}

Because of the diversity of mechanisms by which ischaemic myelopathy developed in this series of patients, each of the aetiological groupings will be discussed separately.

\section{Myelopathy following surgical manipulation or traumatic laceration of the aorta}

In accordance with the experience of others (Watson, 1981), surgical procedures on or traumatic rupture of the aorta accounted for only a very small percentage of the paraplegics admitted to our spinal cord injury service. Paraplegia after resection of an abdominal aortic aneurysm is said to be particularly uncommon (Szilagyi, 1978; Keye, 1980), the likelihood of spinal cord injury being greater after thoracic aneurysm repair (Ross, 1985). Although the length of time that the aorta can be cross-clamped without producing spinal cord damage is a matter of debate, Adams and van Geertruyden (1956) and Cunningham (1982) estimated the upper limits of tolerance to be about 18 minutes, whereas Katz et al. (1981) felt that a bypass shunt should be placed if more than 30 minutes of aortic cross-clamping is anticipated.

Pathologically, cross-clamping of the abdominal aorta during insertion of a graft often leads to a pattern of central spinal cord necrosis with relative sparing of the white matter (Hogan and Romanul, 1966) that is similar to that observed in our case 3 and to that described following infrarenal aortic occlusion in rabbits (DeGirolami and Zivin, 1982). The predominance of damage to the lower motor neuron undoubtedly accounts for the flaccid nature of the weakness in 7 of the 8 patients in this group, and the completeness of the paralysis is most likely related to the extent of the necrosis within the spinal anterior horns. 


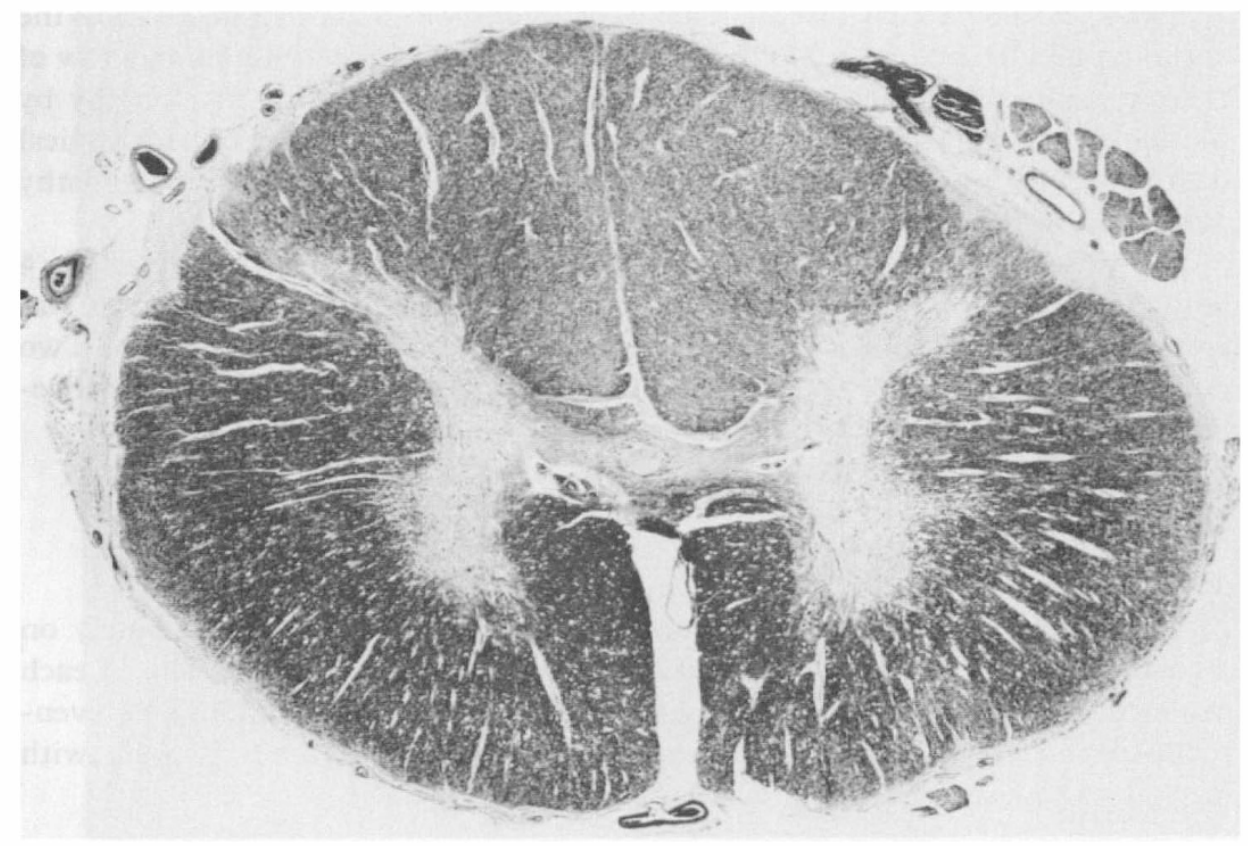

Figure 3 Case 14. Low-power photomicrograph of spinal cord at L2, showing extensive necrosis of grey matter. Note the sparing of the commissural grey (Kluver-Barrera stain $\times 18)$.

\section{Myelopathy following intercostal artery ligation}

Myelopathy has been described on several occasions following rib resections for sympathectomy (Mosberg et al., 1954; Nathan, 1956; Hughes and MacIntyre, 1963) and following thoracoplasty for tuberculosis (Rouquès and Passelecq, 1957) and thoracotomy (Thomas and Dwyer, 1950; Garland et al., 1966, case 2). It is presumed that spinal cord damage is due to operative interruption of blood flow through a major intercostal tributary to the anterior spinal artery, such as that giving rise to the great anterior radicular artery. The very few detailed pathological studies that are available would seem to indicate that this form of myelopathy is due to infarction in the territory of supply of the anterior spinal artery (Hughes and MacIntyre, 1963).

\section{Myelopathy following aortic aneurysm dissection}

Six per cent or less of patients with aortic aneurysm dissections present with paraplegia, and this complication is encountered with a slightly higher degree of frequency among those who have been treated surgically (Hirst et al., 1958; DeBakey et al., 1982), presumably because of the superadded effects of crossclamping of the aorta.

Thompson (1956) reviewed the neuropathological findings in patients in which there was no history of surgical intervention and found that, in most instances, the pattern of spinal cord damage was one of extensive necrosis of grey matter with relative sparing of the peripheral white matter, similar to the 
findings in our case 11. In a few instances, however (e.g. Weisman and Adams, 1944), infarction in the territory of supply of the anterior spinal artery was observed.

Theoretically, spinal cord infarction that develops in association with aortic aneurysm dissection may do so either on the basis of an overall reduction in spinal cord perfusion (in a manner analogous to that following surgical crossclamping of the aorta), in which case there may be central spinal cord necrosis with relative sparing of the white matter, or as a result of tearing or obstruction of a critical intercostal or lumbar arterial tributary, in which case there may be territorial infarction, e.g. in the distribution of supply of the anterior spinal artery.

All 3 of the patients in this group (III) developed persistent flaccid weakness that was probably due to lower motor neuron damage.

\section{Myelopathy following myocardial infarction and/or cardiac arrest}

Myelopathy is a well recognised complication of systemic circulatory failure and has been described in association with coronary thrombosis (Madow and Alpers, 1949; Garland et al., 1966, case 1; Silver and Buxton, 1974), cardiac arrest (Zülch and Behrend, 1961; Silver and Buxton, 1974), shock (Levy and Strauss, 1942; Silver and Buxton, 1974; Blumbergs and Byrne, 1980), and oral antihypertensive therapy (Brown et al., 1987).

The few descriptions that are available of the pathological findings (Madow and Alpers, 1949; Zülch and Behrend, 1961) indicate that, like our case 14, central spinal cord necrosis predominates, with relative sparing of the peripheral white matter. Damage to spinal anterior horns therefore accounts for the flaccid,. lower motor neuron type of weakness that was seen.

\section{Ischaemic myelopathy of uncertain type}

The notion that atherosclerosis, in and of itself, may lead to the development of myelopathy has been slow to gain widespread acceptance, probably in large part because pathological confirmation is difficult to achieve if a very careful postmortem examination is not undertaken. Clinically the disorder affects elderly subjects with a history of heart disease. The onset of illness tends to be more protracted than that of most other forms of myelopathy, and may stretch over a period of weeks or months. Typically there are signs of both upper and lower motor neuron involvement. Pathologically, there are multiple irregular foci of pallor, rarefaction, and infarct-like necrosis in both grey and white matter (Hughes and Brownell, 1966; Jellinger and Neumayer, 1962; Fieschi et al., 1970). Atheromatous emboli may be observed within spinal intraparenchymal (Herrick and Mills, 1971), anterior spinal (Laguna and Cravioto, 1973), or lumber or intercostal arteries (Wolman and Bradshaw, 1968).

The majority of the cases within this group do not conform to the typical clinical presentation of atherosclerotic myelopathy. Nonetheless, we believe that the myelopathy is most likely to have been vascular in origin. The absence of pathological data, however, precludes more detailed analysis of the factors that may have contributed to the development of spinal cord ischaemia among these patients. 


\section{Myelopathy following decompression sickness}

The paralysis associated with decompression sickness is thought to be due to the release of nitrogen gas bubbles within the spinal canal. Hallenbeck et al. (1975), on the basis of cinevenographic studies in dogs subjected to experimental decompression, felt that epidural venous obstruction was responsible for the haemorrhagic lesions that appeared within the white matter of the spinal cord. Palmer et al. (1976) observed similar lesions in decompressed goats but felt that they were due to arterial obstruction. Haymaker and Johnston (1955), in their studies of human material, believed that the lesions in the spinal white matter resulted from obstruction on both the arterial and venous sides of the circulation.

The pattern of neurological dysfunction observed in our cases (23-25) is similar to that described by others. In a recent series of cases, for example, 7 of 8 subjects with decompression sickness suffered incomplete, spastic paralysis (Frankel, 1977).

\section{Clinical correlations}

After recovery from the initial period of spinal shock, which may last for periods of from 3-4 days up to 6 weeks (Guttmann, 1976), the character of the weakness stabilises, although some degree of additional clinical improvement may follow. When the deficit had stabilised, of the total group of 25 patients, 11 (mainly in groups I-IV) were left with complete flaccid paralysis, reflecting predominant lower motor neuron (anterior horn cell) dysfunction, and 9 (mainly groups $\mathrm{V}$ and VI) were left with incomplete spastic weakness, reflecting predominant upper motor neuron (white matter) damage. A significant degree of recovery of neurological function was seen in only 6 patients (cases $2,16,18,19,23$, and $24)$, all of whom had developed incomplete spastic weakness and none of whom had developed complete loss of sensation below the level of injury.

Ten patients (cases 2, 6-8, 14, 15 and 18-21) suffered from the anterior spinal artery syndrome, namely, paralysis with loss of pain and temperature perception and sparing of position/vibration sensation (Steegman, 1952; Lazorthes, 1972). In 7 of these 10, paralysis was incomplete, and in 5 of the 7 the weakness was of spastic character.

Although all of the autopsied cases $(3,11$, and 14) in this series showed predominantly central (grey matter) necrosis with relative preservation of the white matter, this pattern of damage is not necessarily indicative of the range of alterations in other cases, even for the groups (I, III, and IV) represented. It is likely that, in some instances, such as those in which blood flow through a major radicular artery was impaired, territorial infarction (particularly in the distribution of supply of the anterior spinal artery) has occurred. Clinically, these two patterns of damage would be indistinguishable (Hogan and Romanul, 1966). Additionally, in those subjects (especially in groups V and VI) with incomplete spastic weakness it is likely that most of the damage has been sustained by the white matter.

It is not known precisely how a severe acute reduction in arterial perfusion pressure leads to central spinal cord necrosis affecting predominantly grey matter. It would appear, however, that the spinal grey matter serves as a 
'watershed' zone of arterial supply within which the central arterial branches terminate (Lazorthes, 1972). The relative sparing of the white matter, on the other hand, may possibly be related to the presence of anastomotic interconnections among the perimedullary (surface) arterial branches.

In summary, we believe that our findings, in conjunction with those described in the literature, suggest that acute spinal cord ischaemia due to generalised impairment of perfusion (e.g. shock) preferentially damages grey matter and is associated with a flaccid, lower motor neuron type of weakness, the completeness of which would depend on the longitudinal extent of the lesion. In contrast, localised impairment of flow, such as that seen following obstruction of a major radicular artery, may lead to spinal cord infarction in the territory of supply of a particular vessel such as the anterior spinal artery, in which case a clinical picture indistinguishable from that following hypotension-associated necrosis of the spinal grey would be produced. Ischaemic damage that predominates in the white matter tends to be patchy in its distribution, more frequently microembolic in origin, and somewhat more protracted in its clinical evolution, and typically results in the production of an incomplete, spastic, upper motor neuron type of weakness.

\section{Acknowledgements}

The authors wish to thank Ms Diane Pelisse-Dobbs for excellent secretarial assistance. This study was supported in part by grant ES 02928 from the National Institute of Environmental Health Sciences.

\section{References}

Adams HD, van GeERTRUYden HH 1956 Neurologic complications of aortic surgery. Annals of Surgery 144:575-610.

AdAms JH, Corsellis JAN, Duchen LW 1984 Greenfield's Neuropathology, 4th edn. John Wiley \& Sons, New York.

Adams RD, Victor M 1985 Principles of Neurology, 3rd edn. McGraw-Hill, New York.

Blackwood W 1958 Discussion on vascular disease of the spinal cord. Proceedings of the Royal Society of Medicine 51:543-547.

BLUMBERGS PC, BYRNE E 1980 Hypotensive central infarction of the spinal cord. fournal of Neurology, Neurosurgery, and Psychiatry 43:751-753.

Brown P, Gross M, Harrison M 1987 Paraplegia following oral hypotensive treatment of malignant hypertension. Fournal of Neurology, Neurosurgery, and Psychiatry 50: 104.

Cunningham JN Jr, Laschinger JC, Merkin HA, et al. 1982 Measurement of spinal cord ischemia during operations upon the thoracic aorta: Initial clinical experience. Annals of Surgery 196:285-296.

Davis RL, RoBERTSON DM (eds) 1985 Textbook of Neuropathology. Williams \& Wilkins, Baltimore.

DeBakey ME, McCollum CH, Crawford ES, et al. 1982 Dissection and dissecting aneurysms of the aorta: Twenty-year follow-up of five hundred twenty-seven patients treated surgically. Surgery 92:1118-1134.

DeGirolami U, Zivin JA 1982 Neuropathology of experimental spinal cord ischemia in the rabbit. Fournal of Neuropathology and Experimental Neurology 41:129-149.

Fieschi C, Gottlieb A, DE Carolis V 1970 Ischaemic lacunae in the spinal cord of atherosclerotic subjects. Fournal of Neurology, Neurosurgery, and Psychiatry 33:138-146.

Frankel JL 1977 Paraplegia due to decompression sickness. Paraplegia 14:306-311.

Garland H, GreEnBERG J, HaRriman DGF 1966 Infarction of the spinal cord. Brain 89:645-662.

GutTMANN L 1976 Spinal shock. In: Vinken PJ, BRUYN GW (eds) 1976 Handbook of Clinical Neurology. North-Holland, Amsterdam, vol 26, pp 243-262.

Hallenbeck JM, Bove AA, Elliott DH 1975 Mechanisms underlying spinal cord damage in decompression sickness. Neurology (Minneapolis) 25:308-316. 
Haymaker W, Johnston AD 1955 Pathology of decompression sickness: A comparison of the lesions in airmen with those in caisson workers and divers. Military Medicine 117:285-306.

Henson RA, Parsons M 1967 Ischaemic lesions of the spinal cord: An illustrated review. Quarterly fournal of Medicine 36:205-222.

HeRrick MK, Mills PE Jr 1971 Infarction of spinal cord: Two cases of selective gray matter involvement secondary to asymptomatic aortic disease. Archives of Neurology (Chicago) 24:228241.

Hirst A, Johns V, Kime S 1958 Dissecting aneurysm of the aorta, a review of 505 cases. Medicine 37:217-279.

Hogan EL, Romanul FCA 1966 Spinal cord infarction occurring during insertion of aortic graft. Neurology (Minneapolis) 16:67-74.

Hughes JT, BRownell B 1964 Cervical spondylosis complicated by anterior spinal artery thrombosis. Neurology (Minneapolis) 14:1073-1077.

Hughes JT, Brownell B 1966 Spinal cord ischemia due to arteriosclerosis. Archives of Neurology (Chicago) 15:189-202.

Hughes JT, MACINTYRE AG 1963 Spinal cord infarction occurring during thoracolumbar sympathectomy. Fournal of Neurology, Neurosurgery, and Psychiatry 26:418-421.

JELLINGER K, NeUMAYER E 1962 Myélopathie progressive d'origine vasculaire: contribution anatomoclinique aux syndromes d'une hypovascularisation chronique de la moelle. Acta Neurologica Belgica 62:944-956.

KatZ NM, Blackstone EH, KiRKLIN JW, KARP RB 1981 Incremental risk factors for spinal cord injury following operation for acute traumatic aortic transection. Fournal of Thoracic and Cardiovascular Surgery 81:669-674.

Keye G, Bulger J, Shanik G 1980 Paraplegia following abdominal aneurysmectomy. Irish Fournal of Medical Science 149:165-166.

LAGUNa J, Cravioto H 1973 Spinal cord infarction secondary to occlusion of the anterior spinal artery. Archives of Neurology 28:134-136.

LAZORTHES G 1972 Pathology, classification and clinical aspects of vascular diseases of the spinal cord. In: VinkeN PJ, BRUYN GW (eds) 1972 Handbook of Clinical Neurology. North-Holland, Amsterdam, vol 12, pp 492-506.

LEVY NA, STRAuss HA 1942 Myelopathy following compression of abdominal aorta for postpartum hemorrhage: Report of case. Archives of Neurology and Psychiatry 48:85-91.

MADOW L, ALPERS BJ 1949 Involvement of the spinal cord in occlusion of the coronary vessels. Archives of Neurology and Psychiatry (Chicago) 61:430-440.

MANNEN T 1966 Vascular lesions in the spinal cord in the aged: A clinicopathological study. Geriatrics 21:151-160.

MosBerg WH Jr, Voris HC, DUfFy J 1954 Paraplegia as a complication of sympathectomy for hypertension. Annals of Surgery 139:330-334.

NATHAN PW 1956 Reference of sensation at the spinal level. Fournal of Neurology, Neurosurgery, and Psychiatry 19:88-100.

Palmer AC, Blakemore WF, Greenwood AG 1976 Neuropathology of experimental decompression sickness (dysbarism) in the goat. Neuropathology and Applied Neurobiology 2:145156.

Ross RT 1985 Spinal cord infarction in disease and surgery of the aorta. The Canadian fournal of Neurological Sciences 12:289-295.

RouQuès L, PASSElecQ A 1957 Syndrome de Brown-Séquard après thoracoplastie. Revue Neurologique (Paris) 97:146-147.

Silver JR, Buxton PH 1974 Spinal stroke. Brain 97:539-550.

Skinhøj E 1954 Arteriosclerosis of the spinal cord. Acta Psychiatrica Scandinavica 29:139-144.

SteEgmanN AT 1952 Syndrome of the anterior spinal artery. Neurology (Minneapolis) 2:15-39.

Szilagyi DE, Hageman JH, SMith RF, et al. 1978 Spinal cord damage in surgery of the abdominal aorta. Surgery 83:38-56.

Thomas P, Dwyer CS 1950 Postoperative flaccid paraplegia: Case report. Anesthesiology 11:635636.

THOMPSON GB 1956 Dissecting aortic aneurysm with infarction of the spinal cord. Brain 79:111118.

Watson N, 1981 A survey of non-traumatic paraplegia. Paraplegia 19:107-110.

WESIMAN AD, ADAMS RD 1944 The neurological complications of dissecting aortic aneurysm. Brain 67:69-92.

Wolman L, Bradshaw P 1968 Chronic ischaemic myelopathy in aortic atherosclerosis. Paraplegia 6:32-41.

ZüLCH KJ, BEHREND CH 1961 Pathogenesis and topography of anoxia, hypoxia, and ischemia of the brain in man. In: MEYER JS, GASTAUT H (eds) Cerebral Anoxia and Electroencephalogram. Thomas, Springfield, pp 141-163. 